\title{
Update on critical care for acute spinal cord injury in the setting of polytrauma
}

\author{
*John K. Yue, BA,, Ethan A. Winkler, MD, PhD,, Jonathan W. Rick, BS, ${ }^{1,2}$ Hansen Deng, BA, ${ }^{1,2}$ \\ Carlene P. Partow, BS, ${ }^{1,2}$ Pavan S. Upadhyayula, BA, ${ }^{3}$ Harjus S. Birk, MD, ${ }^{3}$ Andrew K. Chan, MD, ${ }^{1,2}$ \\ and Sanjay S. Dhall, MD ${ }^{1,2}$
}

\begin{abstract}
1Department of Neurological Surgery, University of California, San Francisco; ${ }^{2}$ Brain and Spinal Injury Center, Zuckerberg San Francisco General Hospital, San Francisco; and ${ }^{3}$ Department of Neurological Surgery, University of California, San Diego, California
\end{abstract}

\begin{abstract}
Traumatic spinal cord injury (SCl) often occurs in patients with concurrent traumatic injuries in other body systems. These patients with polytrauma pose unique challenges to clinicians. The current review evaluates existing guidelines and updates the evidence for prehospital transport, immobilization, initial resuscitation, critical care, hemodynamic stability, diagnostic imaging, surgical techniques, and timing appropriate for the patient with $\mathrm{SCl}$ who has multisystem trauma. Initial management should be systematic, with focus on spinal immobilization, timely transport, and optimizing perfusion to the spinal cord. There is general evidence for the maintenance of mean arterial pressure of $>85 \mathrm{~mm} \mathrm{Hg}$ during immediate and acute care to optimize neurological outcome; however, the selection of vasopressor type and duration should be judicious, with considerations for level of injury and risks of increased cardiogenic complications in the elderly. Level II recommendations exist for early decompression, and additional time points of neurological assessment within the first 24 hours and during acute care are warranted to determine the temporality of benefits attributable to early surgery. Venous thromboembolism prophylaxis using low-molecular-weight heparin is recommended by current guidelines for SCl. For these patients, titration of tidal volumes is important to balance the association of earlier weaning off the ventilator, with its risk of atelectasis, against the risk for lung damage from mechanical overinflation that can occur with prolonged ventilation. Careful evaluation of infection risk is a priority following multisystem trauma for patients with relative immunosuppression or compromise. Although patients with polytrauma may experience longer rehabilitation courses, long-term neurological recovery is generally comparable to that in patients with isolated $\mathrm{SCl}$ after controlling for demographics. Bowel and bladder disorders are common following SCl, significantly reduce quality of life, and constitute a focus of targeted therapies. Emerging biomarkers including glial fibrillary acidic protein, $\mathrm{S} 100 \beta$, and microRNAs for traumatic SCls are presented. Systematic management approaches to minimize sources of secondary injury are discussed, and areas requiring further research, implementation, and validation are identified.
\end{abstract}

https://thejns.org/doi/abs/10.3171/2017.7.FOCUS17396

KEY WORDS critical care; functional outcome; hemodynamic stability; polytrauma; prehospital management; risk factors; spinal cord injury; spine surgery

$\mathrm{T}$ RAUMATIC spinal cord injuries (SCIs) cause high morbidity and mortality worldwide; the annual incidence is 40 cases per million in the US alone..$^{58}$ Common mechanisms include vehicular crashes, followed by falls, violence, and sports and/or other recreational ac- tivities. ${ }^{58} \mathrm{Up}$ to $80 \%$ of patients with SCI suffer multisystem trauma, defined as an Abbreviated Injury Scale (AIS) score of $\geq 3$ in more than one body region, or an Injury Severity Score $\geq 16 .{ }^{11}$ Patients with SCI suffering polytrauma require special considerations due to the risk of second-

ABBREVIATIONS AANS = American Association of Neurological Surgeons; AIS $=$ Abbreviated Injury Scale; BASIC $=$ Brain and Spinal Injury Center; CNS $=$ Congress of Neurological Surgeons; DLC = discoligamentous complex; DVT = deep venous thrombosis; GFAP = glial fibrillary acidic protein; LOS = length of stay; MAP = mean arterial pressure; $\mathrm{miR}=$ microRNA; $\mathrm{PC}=$ principal component; $\mathrm{PLC}=$ posterior ligamentous complex; $\mathrm{SCl}=$ spinal cord injury; SLIC = Subaxial Cervical Spine Injury Classification and Severity Score; TLICS = Thoracolumbar Injury Classification and Severity Score; UTI = urinary tract infection; $\mathrm{V}_{T}=$ tidal volume.

SUBMITTED June 5, 2017. ACCEPTED July 31, 2017.

INCLUDE WHEN CITING DOI: 10.3171/2017.7.FOCUS17396.

* Mr. Yue and Dr. Winkler contributed equally to this work. 
ary cord injury from hypoperfusion and hypoxemia. Upon stabilization, decisions for surgical decompression and/or spinal column stabilization remain especially challenging for polytrauma patients. Figure 1 displays the range of comorbid and/or multisystem injuries suffered by a patient with SCI and polytrauma. This review examines current best practices and recommendations for the evaluation and management of polytraumatic SCI, and identifies important areas for future research.

\section{Immobilization During Prehospital Transport}

Although there is expert consensus for immobilizing the spine after acute injury, data to determine standards for immobilization during emergency transport remain sparse and inconclusive. Biomechanical studies recommend the combination of a rigid cervical collar with supportive blocks on a hard backboard with straps. ${ }^{15} \mathrm{Ab}-$ dominal straps fastened to the backboard reduce lateral thoracolumbar spinal motion, and excess slack between the patient and backboard should be eliminated to reduce further injury. ${ }^{64}$ However, tissue necrosis may occur from pressure of the rigid backboard during prolonged transport, and/or short periods of rigid immobilization. A padded board may reduce the risk for pressure necrosis by relieving the excess pressure between the board surface and the occiput and/or sacrum. Although cervical stabilization protocols are implemented in many health care systems, there are limited data to suggest true benefit. ${ }^{55}$ Generally, immobilization protocols are ubiquitous across health care institutions, are relatively easy to standardize and implement, and are unlikely to have negative effectsprovided they do not interfere with rapid patient transport to a trauma center, and do not produce pressure ulcers. ${ }^{61}$

\section{Initial Stabilization and Resuscitation}

Following SCI, early intubation and ventilation is indicated for patients with high cervical injuries (C1-5) causing impaired diaphragmatic breathing, respiratory depression, and $\mathrm{CO}_{2}$ retention-these patients are commonly quadriplegic. More than $20 \%$ of patients with cervical SCI require tracheostomy for chronic respiratory insufficiency, and tracheostomy rates are higher in complete (vs incomplete) spinal cord lesions.7 At a Level I trauma center, intubation and tracheostomy were performed in $68 \%$ and $69 \%$, respectively, of patients with low cervical SCI (C6-7). ${ }^{38}$ The authors recommended mandatory early intubation for any patient with complete lower cervical spine injury, and report that even in patients with incomplete cord injuries, $50 \%$ may need tracheostomy.

Evidence regarding optimal intubation techniques for suspected cervical SCI remains controversial. A 2011 systematic review found that cervical movement is reduced from manual in-line stabilization in which a Miller blade is used with direct or indirect laryngoscopy, which should be the standard airway intervention technique in patients with polytrauma who have SCI and vertebral injury. ${ }^{2}$ It is important to note that these recommendations were based on assessment of cervical movement rather than patient outcomes - the perceived benefit of reduced cervical motion may not outweigh the increased time of intubation with indirect methods. Another caveat is the sparse data on prehospital intubation, where indirect viewing methods are largely unavailable.

Pulmonary complications are the leading short- and long-term cause of morbidity and mortality after SCI, also impacting the hospitalization length and costs. Patients who are ventilator dependent have approximately half the life expectancy of those who are similarly injured but not ventilator dependent. ${ }^{21}$ The 2005 Consortium for Spinal Cord Medicine's Clinical Practice Guidelines on Respiratory Management Following Spinal Cord Injury recommends the use of high tidal volume (VT; 20-25 $\mathrm{ml} / \mathrm{kg}$ ideal body weight). ${ }^{19}$ High $\mathrm{V}_{\mathrm{T}}$ is reportedly associated with earlier weaning off of mechanical ventilation and more rapid resolution of atelectasis in patients with SCI. ${ }^{10,62,75}$ In patients without SCI who are at risk for acute respiratory distress syndrome, studies have focused on the safety of high VT ventilation and the risk for barotrauma. ${ }^{9}$ Recently, the safety and efficacy regarding high $\mathrm{VT}_{\mathrm{T}}$ in patients with SCI has been debated, particularly because of the prevalence of acute respiratory distress syndrome in these patients.

Upon securing the airway and establishing adequate oxygenation, circulation should be assessed. As mentioned previously, polytraumatic SCI is often complicated by systemic hypotension due to hemorrhagic and/or neurogenic shock, which worsen secondary neurological injury. Common sources of occult internal hemorrhage include chest wall injury (associated with thoracic SCI), retroperitoneal hemorrhage, pelvic fractures, and open long-bone fracture. Special attention should be paid to the patient with polytrauma who has a pelvic fracture. ${ }^{24}$ Angiographically guided embolization is the first-line treatment for pelvic bleeding, although this may be less effective in treating venous sources..$^{45}$ Of the alternative therapies, open reduction with internal fixation is considered more stable, and can be used in conjunction with closed reduction with external fixation for hemorrhage control. ${ }^{24}$

\section{Spinal Cord Perfusion and Vasopressor Support}

Hypotension and/or neurogenic shock should be treated with aggressive fluid resuscitation. ${ }^{60}$ Suggested therapeutic targets include systolic blood pressure of 90-100 $\mathrm{mm} \mathrm{Hg}$, heart rate of 60-100 beats/minute, urine output $>30 \mathrm{ml} /$ hour, and normothermia. ${ }^{72}$ The joint guidelines of the American Association of Neurological Surgeons (AANS) and the Congress of Neurological Surgeons (CNS) for cervical spine injury management recommend mean arterial pressure (MAP) $>85 \mathrm{~mm} \mathrm{Hg}$ and avoidance of systolic blood pressure $<90 \mathrm{~mm} \mathrm{Hg}$ for the first 5-7 days after SCI. More recently, results show that patients with complete SCI may derive greater benefit from MAP augmentation. ${ }^{14}$ The timing of intervention, and the duration for which MAP values are below threshold, may additionally influence neurological outcome. Similarly, a systematic review by Sabit et al. of the effect of MAP on functional outcome revealed that achieving normotension is the most effective treatment for the patient with SCI. ${ }^{67}$ This indicates the need for further research toward 


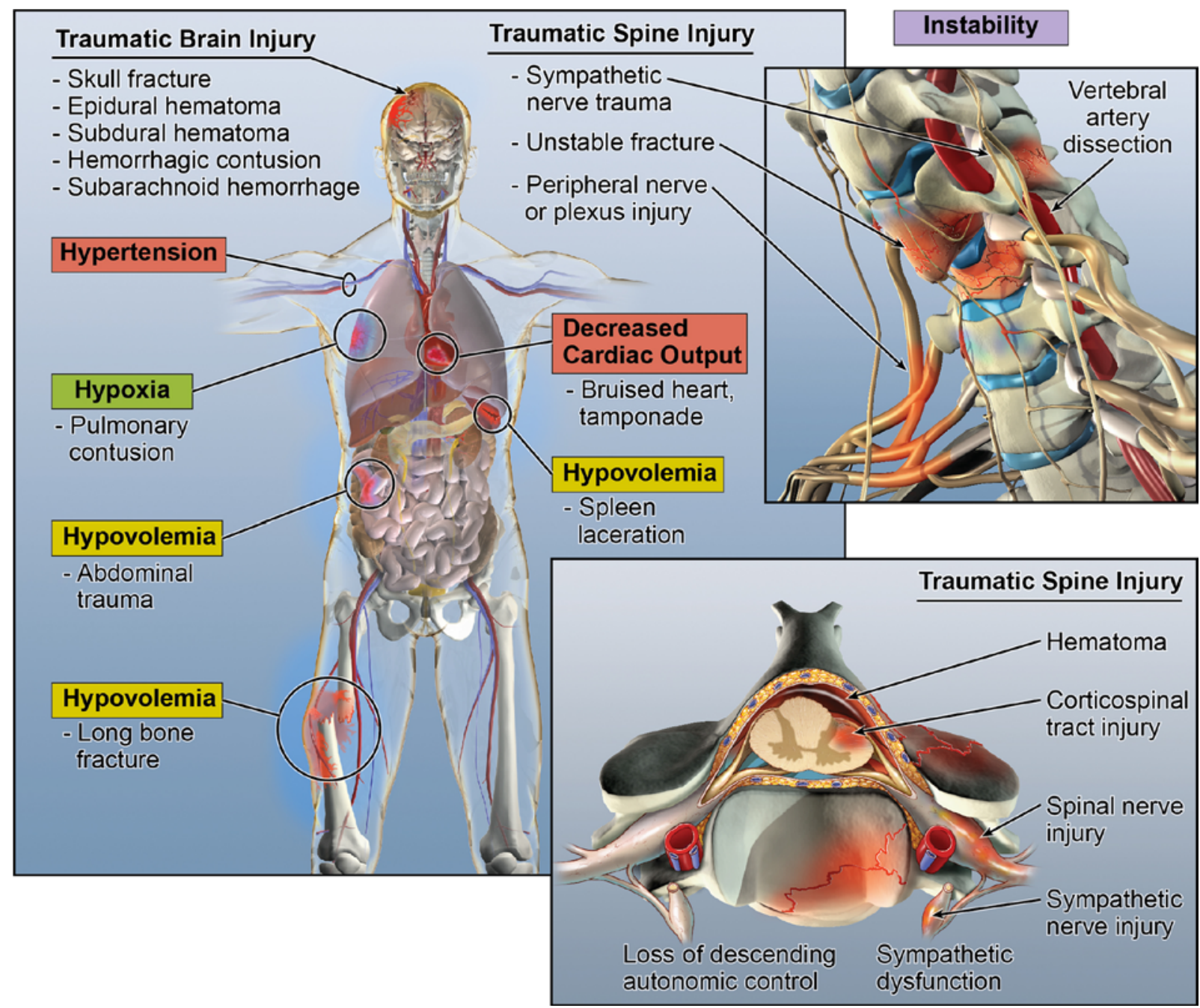

FIG. 1. Types of comorbid and/or multisystem injuries suffered by patients with polytrauma and SCI. Copyright Sanjay S. Dhall. Published with permission.

establishing MAP goals in the care of the patient with polytrauma.

The Consortium for Spinal Cord Medicine recommends vasopressor choice by SCI level. Given the occurrence of bradyarrhythmias due to unopposed vagal tone in high cervical/thoracic injuries, agents with both $\alpha$ - and $\beta$-adrenergic activity (e.g., dopamine, norepinephrine) should be used to maintain MAP goals. In contrast, agents with pure $\alpha$-adrenergic activity such as phenylephrine are adequate for lower thoracic injuries in which hypotension is more likely to result from vasodilation..$^{20}$ In patients with acute traumatic central cord syndrome, high rates of cardiogenic complications are independently associated with dopamine and phenylephrine, and more serious complications were associated with dopamine use in elderly patients. ${ }^{42}$ Higher complication rates have been reported when vasopressors were used contrary to guidelines: e.g., use of dopamine for injuries below T-6. ${ }^{76}$ Interestingly, in a small study of 11 patients, norepinephrine was found to increase cord perfusion pressure by $2 \mathrm{~mm} \mathrm{Hg}$ compared with dopamine, ${ }^{2}$ which may be of clinical advantage in maintaining strict MAP goals during acute care. Evidence from the trauma literature would suggest that narrowing vasopressor choice by injury level (e.g., above or below T-6), age (e.g., elderly patient with autonomic impairment), and presence of comorbidities (e.g., dopamine potentiation of arrhythmias), as well as careful titration of vasopressor dosage to minimize the duration of below-threshold MAPs during the first 5-7 days after injury, are of high importance.

It should be noted that following penetrating SCI, there is a decreased likelihood of neurological improvement, with implications for the role of MAP management using vasopressors. ${ }^{66}$ Aggressive cardiopulmonary management following multisystem trauma involving the spinal cord should weigh equipoise between expected risk of complications and relatively lower likelihoods of recovery.

\section{Imaging Methods}

Diagnostic imaging and workup should be pursued following initial stabilization. Guidelines recommend a 
thorough evaluation of the patient with SCI and high-risk presentation (e.g., male sex, age $<45$ years, impairment on the Glasgow Coma Scale, and chest injury from falls $>10$ feet or due to motor vehicle accidents $>45$ miles per hour). ${ }^{18}$ Computed tomography is the first-line imaging for the patient with SCI and polytrauma, because it provides rapid imaging with improved visualization of bony fractures. Vertebral column instability secondary to ligamentous injury should be evaluated, and flexor and extensor views should be obtained if the cervical spine is involved. Magnetic resonance imaging_in particular the sagittal T2-weighted sequence-has become the gold standard to evaluate active spinal cord compression or vascular injury (e.g., spinal cord hemorrhage, contusion, ischemia, infarct, and/or edema), as well as evidence of associated acute ligamentous injury, including traumatic injuries to intervertebral discs and the posterior ligamentous complex (PLC). ${ }^{47}$ Because MRI is only suitable for those who are hemodynamically stable, this can present a challenge in the patient with polytrauma. The prognostic ability of fat-suppressed T2-weighted MRI to detect acute changes seen in ligamentous injury decreases with time following trauma. As edema expands with time, the ability of serial T2-weighted sagittal MRI to accurately assess lesion severity decreases accordingly.

The traditional classification system for SCI on T2weighted MRI consists of Patterns 1-4 (1, normal cord signal; 2, hyperintense intramedullary edema with longitudinal extent at a single vertebral level; 3 , multilevel edema; and 4, mixed hemorrhage and edema) to correlate with injury severity and outcome. ${ }^{3,34}$ However, in the setting of nonhemorrhagic traumatic SCI (Pattern 3 edema), there is insufficient correlation between longitudinal edema and functional recovery. ${ }^{6}$ Accordingly, the Brain and Spinal Injury Center (BASIC) score was developed in 2015, and it is an ordinal scale ranging from 0 to 4 , classifying the extent of transverse injury following blunt cervical SCI ( 0 , no appreciable intramedullary cord signal abnormality; 1 , intramedullary $\mathrm{T} 2$ hyperintensity confined to central gray matter; 2 , intramedullary $\mathrm{T} 2$ hyperintensity extending to involve spinal white matter, but not involving the entire transverse extent of the spinal cord; 3 , intramedullary T2 hyperintensity involving the entire transverse extent of the spinal cord; and 4, Grade 3 injury plus discrete T2 hypointense foci, consistent with macrohemorrhage). This scale showed strong correlations with AIS grade both at admission and at discharge, with high interrater reliability (kappa 0.81-0.83) ${ }^{69}$ The stratification of SCI by using the extent of transverse T2 pathology shows promise in enhancing injury classification as well as outcome prediction.

Among advanced neuroimaging modalities, fractional anisotropy on diffusion tensor imaging showed the strongest evidence as a possible emerging biomarker of functional disability across degenerative cord etiologies and SCI, ${ }^{53}$ but it remains below diagnostic sensitivity and specificity thresholds for qualification.

More recently, nonlinear principal component (PC) analysis was used to assess the relationship between early MRI biomarkers ( $<24$ hours) and their predictive validity on neurological impairment following cervical SCI. ${ }^{37}$ The 2 PCs are PC1, which is represented by all imaging vari- ables, with measures of intrinsic cord compression (BASIC score, linear length of injury, sagittal grade) showing highest loadings; and PC2, which is represented by markers of extrinsic cord compression. The $\mathrm{PCl}$ predicted AIS at discharge, and among its components, the BASIC score consistently demonstrated the strongest distinction between severe, moderate, and mild AIS grading. In a smaller study by the same authors on thoracolumbar injury, markers of extrinsic cord compression highly correlated with surgical decompression. ${ }^{51}$ Together, these studies support the role of T2-weighted MRI and emerging statistical tools to delineate clusters of multidimensional risk factors impacting critical care decisions and outcome following multisystem injury.

\section{Surgical Candidacy and Approach}

A number of factors influence the timing and choice of surgical management in the patient with polytrauma who has SCI. The 2005 Thoracolumbar Injury Classification and Severity Score (TLICS) and the 2007 Subaxial Cervical Spine Injury Classification and Severity Score (SLIC) have been widely adopted to guide surgical decision making. ${ }^{23,71}$ Both TLICS and SLIC incorporate the same 3 categories of injury characteristics: injury morphology, integrity of the PLC or discoligamentous complex (DLC), and neurological status (Table 1). ${ }^{44,63}$ The TLICS and SLIC sum the patient score in each category, and the final score determines the next treatment step. A score $<4$ suggests nonoperative management, 4 is borderline, and $>4$ is an indication for operative management. Evidence for the safety of TLICS and SLIC has been widely studied in both adult and pediatric populations. ${ }^{43}$

TABLE 1. Comparison of TLICS and SLIC systems

\begin{tabular}{|c|c|c|c|}
\hline \multicolumn{2}{|l|}{ TLICS } & \multicolumn{2}{|l|}{ SLIC } \\
\hline Characteristic & Score & Characteristic & Score \\
\hline Injury morphology & & njury morphology & \\
\hline No abnormality & 0 & No abnormality & 0 \\
\hline Compression & 1 & Compression & 1 \\
\hline Burst component & 2 & Burst component & 2 \\
\hline Translation/rotation & 3 & Translation/rotation & 3 \\
\hline Distraction & 4 & Distraction & 4 \\
\hline PLC integrity & & LC integrity & \\
\hline Intact & 0 & Intact & 0 \\
\hline Indeterminate & 2 & Indeterminate & 1 \\
\hline Disrupted & 3 & Disrupted & 2 \\
\hline Neurological status & & Jeurological status & \\
\hline Intact & 0 & Intact & 0 \\
\hline Nerve root injury & 2 & Nerve root injury & 1 \\
\hline Complete cord injury & 2 & Complete cord injury & 2 \\
\hline Incomplete cord injury & 3 & Incomplete cord injury & 3 \\
\hline Cauda equina injury & 3 & & \\
\hline
\end{tabular}

The TLICS and SLIC are used by summing the patient score in each category and using the final score to determine the next treatment step. For each scoring system, a score $<4$ suggests nonoperative management, 4 is borderline, and $>4$ is an indication for operative management. 
The surgical objectives are to achieve mechanical stability and to prevent neurological deterioration. In general, patients with incomplete neurological injury should undergo an anterior procedure in the setting of anterior neural compression and an undisrupted PLC. If the PLC or DLC is disrupted with evidence of nerve root injury, but the patient is overall neurologically intact, a posterior procedure may be more appropriate. In patients presenting with incomplete neurological injury and PLC disruption, a combined anterior-posterior approach is indicated. For complete neurological injury, aggressive decompression is generally performed in an effort to maximize neurological recovery. Reconstruction and/or fixation of the vertebral column can be performed to restore CSF flow. Important considerations are the site of compression, morphology of injury, risk for progressive deformity, and surgical team experience with anterior, posterior, and combined techniques.

\section{Surgical Timing}

The timing of surgical intervention remains under debate. There is consensus that nonneurological outcome measures such as hospital and ICU length of stay (LOS), duration of mechanical ventilation, and pneumonia and other complications improve in patients undergoing early surgical stabilization ${ }^{13,16}$-more markedly in patients with polytrauma and thoracic injuries. ${ }^{13}$ Whether early surgical intervention improves neurological outcomes is less clear. Whereas historical trials show no benefit to early $(<$ 24 hours from time of injury) surgical intervention, more recent studies report improved motor and neurological recovery ${ }^{46}$ Notably, the prospective multicenter Surgical Timing in Acute Spinal Cord Injury Study trial conducted from 2002 to 2009 reports improved AIS grades among patients with acute cervical SCI who underwent early versus late surgery. ${ }^{27}$ This is supported by the systematic review by Lenehan and colleagues showing improved odds of 6- and 12-month functional outcome following early surgery ${ }^{48}$ Early decompression has also been found to be more cost-effective than later surgery for patients with motor-complete and -incomplete SCI. ${ }^{28}$ Moreover, incomplete resuscitation of patients prior to surgery may confound the influence of surgical timing on morbidity and mortality. ${ }^{25,26}$

Under the general consensus of "early" being $<24$ hours, a recent meta-analysis of 5326 patients identified benefit to early compared with late spinal cord decompression, ${ }^{25}$ also noting the considerable heterogeneity of patients and medical practice across studies. The best that current evidence can provide is Level II recommendations for early decompression. ${ }^{29}$ Additionally, more refined time points within the first 24 hours are warranted to assess the temporality of early surgical benefits. It is possible that the effects of early intervention may wane within the first 24 hours, further delineating the need for large, well-controlled prospective studies within this time range.

\section{Biomarkers for Early Diagnosis}

There is increasing interest in identifying biomarkers for the early diagnosis of SCI. Candidate markers for trau- matic SCI include glial fibrillary acidic protein (GFAP), neurofilaments, cleaved tau, myelin basic protein, neuronspecific enolase, S100 $\beta$, and soluble CD95 ligand. ${ }^{4,17,41}$ To date, $S 100 \beta-$ a calcium-binding protein in astroglial and Schwann cells-is the most studied, showing elevations after traumatic SCI or vertebral fractures. Serum S100 $\beta$ and neuron-specific enolase have been shown to increase after polytrauma, hemolysis, and/or inadequate resuscitation..$^{50}$ Some experts have proposed using biomarkers to assess injury severity and treatment response rather than for diagnosis, due to low specificity.

Biomarkers may indicate transient or permanent neurological deficit due to systemic injuries. For example, GFAP also correlated with delayed-onset paraplegia. ${ }^{74}$ Findings indicate that $S 100 \beta$ and GFAP have potential as biomarkers when evaluating stability of the patient with polytrauma for investigation of injury severity, for diagnostic imaging, and/or MAP-directed therapy. A polytrauma-specific biomarker in SCI remains elusive. The only study to date comparing patients with traumatic SCI to healthy controls reports nonspecific elevations in GFAP and neurofilaments. ${ }^{35}$ However, a study by Brisby and colleagues found elevated CSF levels of neurofilaments and S100 $\beta$ following disc herniation, and patients with symptom duration $<3$ months showed higher neurofilament levels compared with patients with $\geq 3$ months' duration. ${ }^{8}$ Hence, GFAP and neurofilaments may indicate nerve root compression during acute trauma, but this remains to be validated in larger samples.

MicroRNAs (miRs) are emerging candidates for both diagnostic biomarkers and therapeutic targets for SCI. Notably, miR-21 may be important due to its role in hypertrophy-to-hyperplasia changes characteristic of astrogliosis. ${ }^{54}$ In the laboratory it has been shown to have antiapoptotic and antiinflammatory properties, although its expression decreases 14 days postinsult. ${ }^{54,59}$ As a novel therapeutic agent, miR-21 antagomir administered by intrathecal injection decreased recovery of hindlimb motor function, ${ }^{59}$ and overexpression of miR-21 has been shown to protect against transient ischemia. ${ }^{39}$

\section{Infection Risk}

The patient with polytrauma has increased susceptibility to infection due to the disruption of the neuroimmune axis. Whereas pneumonia and bloodborne infections are the most common causes of death $(33 \%$ of all deaths in the 1st year), urinary tract infections (UTIs) and decubitus ulcers are risk factors for rehospitalization, with incidences of $34 \%$ and $10 \%$, respectively. ${ }^{31}$ A retrospective analysis of 5540 patients undergoing cervical spine surgery and recorded in the US Nationwide Inpatient Sample between 2000 and 2011 reported neurological status (myelopathy or SCI) and trauma as the most significant predictors of surgical site infection. ${ }^{36}$ Surgical approach, number of levels fused, female sex, black race, medium-size hospital, rural hospital, large hospital, western US hospital, and Medicare coverage were additional significant predictors of surgical site infection. ${ }^{36}$ Several studies report decreased infection rates with intrawound vancomycin powder. ${ }^{12,33}$ 


\section{Venous Thromboembolism}

Patients with spinal polytrauma are at risk for venous thromboembolism, most prominently deep venous thrombosis (DVT). Almost $40 \%$ of patients with SCI may suffer DVT within the first 12 weeks following acute injury, often due to stasis and hypercoagulability, which are compounded with multisystem injuries. ${ }^{56}$ Prophylaxis for patients with polytrauma is complicated because of the risk of worsened bleeding. The American College of Chest Physicians ultimately recommends pharmacological anticoagulation, predominantly with low-molecularweight heparin following acute SCI (Grade 1A evidence), combined with mechanical prophylaxis for patients with exceptional bleeding risk. ${ }^{32}$ The 2013 guidelines of the AANS/CNS Joint Section on Disorders of the Spine and Peripheral Nerves reported evidence for pharmacological prophylaxis using low-molecular-weight heparin (Level I), within 72 hours following spinal injury (Level II). ${ }^{22}$ Current guidelines recommend continuing prophylaxis for at least 12 weeks after patient stabilization, at which point the risk of DVT declines considerably. ${ }^{30}$

\section{Bowel and Bladder Disorders}

Spinal cord injury may lead to temporary or permanent bowel and bladder disorders, which can result in UTIs and direct renal damage. For patients with SCI at 1 year postinjury, $40 \%$ attended urology clinic and 33\% were hospitalized due to bladder issues; UTIs accounted for $>20 \%$ of these hospitalizations. ${ }^{70}$ Although procedures such as the Valsalva maneuver may be attempted to induce voiding, current recommendations focus on clean intermittent catheterization. Hughes defined the following 3 different neuropathological patterns of bowel dysfunction: Pattern A, injury above T-7, when voluntary control of abdominal muscles was absent but spinal sacral reflexes were preserved; Pattern B, injury below T-7 with voluntary control of abdominal muscles and preserved sacral reflexes; and Pattern C, injury below T-7 with voluntary control of abdominal muscles and absent sacral reflexes. ${ }^{40}$ First-line therapy involves timed dietary intake and, if needed, rectal stimulation. Pharmacological management with prokinetic laxatives is also an option, and for patients whose condition is refractory, surgical management via colostomy. Patient preference, ability, and resources will play a large role in determining the direction of management.

\section{Functional Outcomes and Role of Rehabilitation Services}

It is generally recognized that patients with traumatic SCIs present with worse functional status than those with nontraumatic SCIs, and patients with polytrauma present with a higher percentage of complete lesions than do those with isolated trauma. ${ }^{65,68}$ Similarly, patients with trauma who have concurrent severe brain injury demonstrate longer LOS and rehabilitation stays, and lower Functional Independence Measure motor scores at discharge compared with those without brain trauma. ${ }^{52}$ However, when comparing SCI with and without polytrauma, the complication rates, discharge destination, neurological recovery, and up to 1-year functional outcome were comparable after adjusting for demographics, lesion level, and AIS grade. ${ }^{65}$ The general consensus is that neurological recovery is dependent on completeness of lesion rather than presence of polytrauma. In smaller studies of SCI resulting in paraplegia, patients with polytrauma demonstrated no differences in neurological improvement compared with their counterparts who had isolated SCI; however, they did demonstrate longer LOS, delayed acquisition of activities of daily living functions, and increased health care costs. ${ }^{65}$ Future prospective studies with appropriate adjustment for SCI morphology and severity, across various levels of polytrauma, are needed.

Physical and occupational therapists serve central roles in patient recovery. In general, rehabilitation following SCI is divided into acute and long-term phases. ${ }^{57}$ In the acute hospital setting, the goals for physical therapy are to prevent muscle contracture and muscle wasting, and to reduce the risk of pressure ulcers. For patients suffering paraplegia, physical therapy often focuses on building upper-extremity strength to assist with mobility. Improvements following physical therapy, along with outcome measures of social integration and functional independence at 1 year postinjury, can be predicted by AIS and treatment duration. ${ }^{73}$

\section{Conclusions}

Spinal cord injury with polytrauma poses uniquely challenging considerations due to the increased risk of secondary insults to the spinal cord. Prehospital management should include appropriate spinal immobilization followed by timely transport to a trauma center. The initial assessment and management are focused on optimizing perfusion to the spinal cord. Poststabilization, diagnostic evaluation includes CT for bony fractures or overt cord pathology, and MRI in the patient with hemodynamic stability. Surgical stabilization depends on approach, timing, and perioperative management. Careful consideration of infection risk should be a priority for patients with trauma who have relative immunosuppression or compromise. Patients with polytrauma may experience longer rehabilitation courses; however, long-term neurological recovery is generally comparable to that for patients with isolated SCI, after controlling for demographics. Biomarkers for SCI may aid in early diagnosis and outcomes prognosis, but they require studies in larger data sets to achieve enough sensitivity and specificity to be suitable as recommendations.

\section{References}

1. Ahn H, Singh J, Nathens A, MacDonald RD, Travers A, Tallon J, et al: Pre-hospital care management of a potential spinal cord injured patient: a systematic review of the literature and evidence-based guidelines. J Neurotrauma 28:13411361,2011

2. Altaf F, Griesdale DE, Belanger L, Ritchie L, Markez J, Ailon T, et al: The differential effects of norepinephrine and dopamine on cerebrospinal fluid pressure and spinal cord perfusion pressure after acute human spinal cord injury. Spinal Cord 55:33-38, 2017

3. Andreoli C, Colaiacomo MC, Rojas Beccaglia M, Di Biasi C, 
Casciani E, Gualdi G: MRI in the acute phase of spinal cord traumatic lesions: Relationship between MRI findings and neurological outcome. Radiol Med (Torino) 110:636-645, 2005

4. Binder LI, Frankfurter A, Rebhun LI: The distribution of tau in the mammalian central nervous system. J Cell Biol 101:1371-1378, 1985

5. Bondurant FJ, Cotler HB, Kulkarni MV, McArdle CB, Harris JH Jr: Acute spinal cord injury. A study using physical examination and magnetic resonance imaging. Spine (Phila Pa 1976) 15:161-168, 1990

6. Bozzo A, Marcoux J, Radhakrishna M, Pelletier J, Goulet B: The role of magnetic resonance imaging in the management of acute spinal cord injury. J Neurotrauma 28:1401-1411, 2011

7. Branco BC, Plurad D, Green DJ, Inaba K, Lam L, Cestero R, et al: Incidence and clinical predictors for tracheostomy after cervical spinal cord injury: a National Trauma Databank review. J Trauma 70:111-115, 2011

8. Brisby H, Olmarker K, Rosengren L, Cederlund CG, Rydevik B: Markers of nerve tissue injury in the cerebrospinal fluid in patients with lumbar disc herniation and sciatica. Spine (Phila Pa 1976) 24:742-746, 1999

9. Brower RG, Matthay MA, Morris A, Schoenfeld D, Thompson BT, Wheeler A: Ventilation with lower tidal volumes as compared with traditional tidal volumes for acute lung injury and the acute respiratory distress syndrome. N Engl J Med 342:1301-1308, 2000

10. Brown R, DiMarco AF, Hoit JD, Garshick E: Respiratory dysfunction and management in spinal cord injury. Respir Care 51:853-870, 2006

11. Burney RE, Maio RF, Maynard F, Karunas R: Incidence, characteristics, and outcome of spinal cord injury at trauma centers in North America. Arch Surg 128:596-599, 1993

12. Caroom C, Tullar JM, Benton EG Jr, Jones JR, Chaput CD: Intrawound vancomycin powder reduces surgical site infections in posterior cervical fusion. Spine (Phila Pa 1976) 38:1183-1187, 2013

13. Carreon LY, Dimar JR: Early versus late stabilization of spine injuries: a systematic review. Spine (Phila Pa 1976) 36:E727-E733, 2011

14. Catapano JS, John Hawryluk GW, Whetstone W, Saigal R, Ferguson A, Talbott J, et al: Higher mean arterial pressure values correlate with neurologic improvement in patients with initially complete spinal cord injuries. World Neurosurg 96:72-79, 2016

15. Chandler DR, Nemejc C, Adkins RH, Waters RL: Emergency cervical-spine immobilization. Ann Emerg Med 21:11851188,1992

16. Chipman JG, Deuser WE, Beilman GJ: Early surgery for thoracolumbar spine injuries decreases complications. J Trauma 56:52-57, 2004

17. Cohen SR, Brooks BR, Herndon RM, McKhann GM: A diagnostic index of active demyelination: myelin basic protein in cerebrospinal fluid. Ann Neurol 8:25-31, 1980

18. Connor D, Greaves I, Porter K, Bloch M: Pre-hospital spinal immobilisation: an initial consensus statement. Emerg Med J 30:1067-1069, 2013

19. Consortium for Spinal Cord Medicine: Clinical Practice Guideline: Respiratory Management Following Spinal Cord Injury: A Clinical Practice Guideline for HealthCare Professionals. Washington, DC: Paralyzed Veterans of America, 2015 (http://www.pva.org/CMSPages/GetFile. aspx?guid=14358316-e534-4d67-b62b-29d2fc94c29c) [Accessed September 15, 2017]

20. Consortium for Spinal Cord Medicine: Early acute management in adults with spinal cord injury: a clinical practice guideline for health-care professionals. J Spinal Cord Med 31:403-479, 2008
21. DeVivo MJ, Krause JS, Lammertse DP: Recent trends in mortality and causes of death among persons with spinal cord injury. Arch Phys Med Rehabil 80:1411-1419, 1999

22. Dhall SS, Hadley MN, Aarabi B, Gelb DE, Hurlbert RJ, Rozzelle CJ, et al: Deep venous thrombosis and thromboembolism in patients with cervical spinal cord injuries. Neurosurgery 72 (Suppl 2):244-254, 2013

23. Dvorak MF, Fisher CG, Fehlings MG, Rampersaud YR, Oner FC, Aarabi B, et al: The surgical approach to subaxial cervical spine injuries: an evidence-based algorithm based on the SLIC classification system. Spine (Phila Pa 1976) 32:2620 2629, 2007

24. Eastridge BJ, Starr A, Minei JP, O'Keefe GE, Scalea TM: The importance of fracture pattern in guiding therapeutic decision-making in patients with hemorrhagic shock and pelvic ring disruptions. J Trauma 53:446-451, 2002

25. El Tecle NE, Dahdaleh NS, Hitchon PW: Timing of surgery in spinal cord injury. Spine (Phila Pa 1976) 41:E995-E1004, 2016

26. Epstein NE, Hollingsworth R: Diagnosis and management of traumatic cervical central spinal cord injury: A review. Surg Neurol Int 6 (Suppl 4):S140-S153, 2015

27. Fehlings MG, Vaccaro A, Wilson JR, Singh A, W Cadotte D, Harrop JS, et al: Early versus delayed decompression for traumatic cervical spinal cord injury: results of the Surgical Timing in Acute Spinal Cord Injury Study (STASCIS). PLoS One 7:e32037, 2012

28. Furlan JC, Craven BC, Massicotte EM, Fehlings MG: Early versus delayed surgical decompression of spinal cord after traumatic cervical spinal cord injury: a cost-utility analysis. World Neurosurg 88:166-174, 2016

29. Furlan JC, Noonan V, Cadotte DW, Fehlings MG: Timing of decompressive surgery of spinal cord after traumatic spinal cord injury: an evidence-based examination of pre-clinical and clinical studies. J Neurotrauma 28:1371-1399, 2011

30. Gaber TAZK: Significant reduction of the risk of venous thromboembolism in all long-term immobile patients a few months after the onset of immobility. Med Hypotheses 64:1173-1176, 2005

31. Garcia-Arguello LY, O'Horo JC, Farrell A, Blakney R, Sohail MR, Evans CT, et al: Infections in the spinal cord-injured population: a systematic review. Spinal Cord 55:526-534, 2017

32. Geerts WH, Bergqvist D, Pineo GF, Heit JA, Samama CM, Lassen MR, et al: Prevention of venous thromboembolism: American College of Chest Physicians Evidence-Based Clinical Practice Guidelines (8th edition). Chest 133:381S-453S, 2008

33. Ghobrial GM, Cadotte DW, Williams K Jr, Fehlings MG, Harrop JS: Complications from the use of intrawound vancomycin in lumbar spinal surgery: a systematic review. Neurosurg Focus 39(4):E11, 2015

34. Goldberg AL, Rothfus WE, Deeb ZL, Daffner RH, Lupetin AR, Wilberger JE, et al: The impact of magnetic resonance on the diagnostic evaluation of acute cervicothoracic spinal trauma. Skeletal Radiol 17:89-95, 1988

35. Guéz M, Hildingsson C, Rosengren L, Karlsson K, Toolanen G: Nervous tissue damage markers in cerebrospinal fluid after cervical spine injuries and whiplash trauma. J Neurotrauma $20: 853-858,2003$

36. Haddad S, Millhouse PW, Maltenfort M, Restrepo C, Kepler CK, Vaccaro AR: Diagnosis and neurologic status as predictors of surgical site infection in primary cervical spinal surgery. Spine J 16:632-642, 2016

37. Haefeli J, Mabray MC, Whetstone WD, Dhall SS, Pan JZ, Upadhyayula P, et al: Multivariate analysis of MRI biomarkers for predicting neurologic impairment in cervical spinal cord injury. AJNR Am J Neuroradiol 38:648-655, 2017

38. Hassid VJ, Schinco MA, Tepas JJ, Griffen MM, Murphy TL, Frykberg ER, et al: Definitive establishment of airway con- 
trol is critical for optimal outcome in lower cervical spinal cord injury. J Trauma 65:1328-1332, 2008

39. He F, Ren Y, Shi E, Liu K, Yan L, Jiang X: Overexpression of microRNA-21 protects spinal cords against transient ischemia. J Thorac Cardiovasc Surg 152:1602-1608, 2016

40. Hughes M: Bowel management in spinal cord injury patients. Clin Colon Rectal Surg 27:113-115, 2014

41. Hulme CH, Brown SJ, Fuller HR, Riddell J, Osman A, Chowdhury J, et al: The developing landscape of diagnostic and prognostic biomarkers for spinal cord injury in cerebrospinal fluid and blood. Spinal Cord 55:114-125, 2017

42. Inoue T, Manley GT, Patel N, Whetstone WD: Medical and surgical management after spinal cord injury: vasopressor usage, early surgerys, and complications. J Neurotrauma 31:284-291, 2014

43. Joaquim AF, de Almeida Bastos DC, Jorge Torres HH, Patel AA: Thoracolumbar Injury Classification and Injury Severity Score System: a literature review of its safety. Global Spine J 6:80-85, 2016

44. Joaquim AF, Fernandes YB, Cavalcante RAC, Fragoso RM, Honorato DC, Patel AA: Evaluation of the thoracolumbar injury classification system in thoracic and lumbar spinal trauma. Spine (Phila Pa 1976) 36:33-36, 2011

45. Karadimas EJ, Nicolson T, Kakagia DD, Matthews SJ, Richards PJ, Giannoudis PV: Angiographic embolisation of pelvic ring injuries. Treatment algorithm and review of the literature. Int Orthop 35:1381-1390, 2011

46. Kreinest M, Ludes L, Türk A, Grützner PA, Biglari B, Matschke S: Analysis of prehospital care and emergency room treatment of patients with acute traumatic spinal cord injury: a retrospective cohort study on the implementation of current guidelines. Spinal Cord 55:16-19, 2017

47. Lee HM, Kim HS, Kim DJ, Suk KS, Park JO, Kim NH: Reliability of magnetic resonance imaging in detecting posterior ligament complex injury in thoracolumbar spinal fractures. Spine (Phila Pa 1976) 25:2079-2084, 2000

48. Lenehan B, Fisher CG, Vaccaro A, Fehlings M, Aarabi B, Dvorak MF: The urgency of surgical decompression in acute central cord injuries with spondylosis and without instability. Spine (Phila Pa 1976) 35 (21 Suppl):S180-S186, 2010

49. Leypold BG, Flanders AE, Schwartz ED, Burns AS: The impact of methylprednisolone on lesion severity following spinal cord injury. Spine (Phila Pa 1976) 32:373-381, 2007

50 Loy DN, Sroufe AE, Pelt JL, Burke DA, Cao QL, Talbott JF, et al: Serum biomarkers for experimental acute spinal cord injury: rapid elevation of neuron-specific enolase and S-100 $\beta$. Neurosurgery 56:391-397, 2005

51. Mabray MC, Talbott JF, Whetstone WD, Dhall SS, Phillips DB, Pan JZ, et al: Multidimensional analysis of magnetic resonance imaging predicts early impairment in thoracic and thoracolumbar spinal cord Injury. J Neurotrauma 33:954962, 2016

52. Macciocchi S, Seel RT, Warshowsky A, Thompson N, Barlow K: Co-occurring traumatic brain injury and acute spinal cord injury rehabilitation outcomes. Arch Phys Med Rehabil 93:1788-1794, 2012

53. Martin AR, Aleksanderek I, Cohen-Adad J, Tarmohamed Z, Tetreault L, Smith N, et al: Translating state-of-the-art spinal cord MRI techniques to clinical use: a systematic review of clinical studies utilizing DTI, MT, MWF, MRS, and fMRI. Neuroimage Clin 10:192-238, 2015

54. Martirosyan NL, Carotenuto A, Patel AA, Kalani MYS, Yagmurlu K, Lemole GM Jr, et al: The role of microRNA markers in the diagnosis, treatment, and outcome prediction of spinal cord injury. Front Surg 3:56, 2016

55. McDonald NE, Curran-Sills G, Thomas RE: Outcomes and characteristics of non-immobilised, spine-injured trauma patients: a systematic review of prehospital selective immobilisation protocols. Emerg Med J 33:732-740, 2016
56. Merli GJ, Crabbe S, Paluzzi RG, Fritz D: Etiology, incidence, and prevention of deep vein thrombosis in acute spinal cord injury. Arch Phys Med Rehabil 74:1199-1205, 1993

57. Nas K, Yazmalar L, Şah V, Aydın A, Öneş K: Rehabilitation of spinal cord injuries. World J Orthop 6:8-16, 2015

58. National Spinal Cord Injury Statistical Center: Facts and Figures at a Glance. Birmingham: University of Alabama at Birmingham, 2013 (https://www.nscisc.uab.edu/ PublicDocuments/fact_figures_docs/Facts\%202013.pdf) [Accessed September 15, 2017]

59. Nieto-Diaz M, Esteban FJ, Reigada D, Muñoz-Galdeano T, Yunta M, Caballero-López M, et al: MicroRNA dysregulation in spinal cord injury: causes, consequences and therapeutics. Front Cell Neurosci 8:53, 2014

60. Oliver M, Inaba K, Tang A, Branco BC, Barmparas G, Schnüriger B, et al: The changing epidemiology of spinal trauma: a 13-year review from a Level I trauma centre. Injury 43:1296-1300, 2012

61. Oteir AO, Smith K, Jennings PA, Stoelwinder JU: The prehospital management of suspected spinal cord injury: an update. Prehosp Disaster Med 29:399-402, 2014

62. Padman R, Alexander M, Thorogood C, Porth S: Respiratory management of pediatric patients with spinal cord injuries: retrospective review of the duPont experience. Neurorehabil Neural Repair 17:32-36, 2003

63. Patel AA, Vaccaro AR: Thoracolumbar spine trauma classification. J Am Acad Orthop Surg 18:63-71, 2010

64. Peery CA, Brice J, White WD: Prehospital spinal immobilization and the backboard quality assessment study. Prehosp Emerg Care 11:293-297, 2007

65. Putz C, Schuld C, Gantz S, Grieser T, Akbar M, Moradi B, et al: The effect of polytrauma as a possible confounder in the outcome of monotraumatic vs polytraumatic paraplegic patients: a clinical cohort study. Spinal Cord 49:721-727, 2011

66. Readdy WJ, Saigal R, Whetstone WD, Mefford AN, Ferguson AR, Talbott JF, et al: Failure of mean arterial pressure goals to improve outcomes following penetrating spinal cord injury. Neurosurgery 79:708-714, 2016

67. Sabit B, Zeiler FA, Berrington N: The impact of mean arterial pressure on functional outcome post trauma-related acute spinal cord injury: a scoping systematic review of the human literature. J Intensive Care Med 34:2583-2594, 2017

68. Scivoletto G, Farchi S, Laurenza L, Tamburella F, Molinari M: Impact of multiple injuries on functional and neurological outcomes of patients with spinal cord injury. Scand $\mathbf{J}$ Trauma Resusc Emerg Med 21:42, 2013

69. Talbott JF, Whetstone WD, Readdy WJ, Ferguson AR, Bresnahan JC, Saigal R, et al: The Brain and Spinal Injury Center score: a novel, simple, and reproducible method for assessing the severity of acute cervical spinal cord injury with axial T2weighted MRI findings. J Neurosurg Spine 23:495-504, 2015

70. Taweel WA, Seyam R: Neurogenic bladder in spinal cord injury patients. Res Rep Urol 7:85-99, 2015

71. Vaccaro AR, Lehman RA Jr, Hurlbert RJ, Anderson PA, Harris M, Hedlund R, et al: A new classification of thoracolumbar injuries: the importance of injury morphology, the integrity of the posterior ligamentous complex, and neurologic status. Spine (Phila Pa 1976) 30:2325-2333, 2005

72. Walters BC, Hadley MN, Hurlbert RJ, Aarabi B, Dhall SS, Gelb DE, et al: Guidelines for the management of acute cervical spine and spinal cord injuries: 2013 update. Neurosurgery 60 (Suppl 1):82-91, 2013

73. Whiteneck G, Gassaway J, Dijkers MP, Heinemann AW, Kreider SED: Relationship of patient characteristics and rehabilitation services to outcomes following spinal cord injury: the SCIRehab project. J Spinal Cord Med 35:484-502, 2012

74. Winnerkvist A, Anderson RE, Hansson LO, Rosengren L, Estrera AE, Huynh TTT, et al: Multilevel somatosensory evoked potentials and cerebrospinal proteins: indicators of 
spinal cord injury in thoracoabdominal aortic aneurysm surgery. Eur J Cardiothorac Surg 31:637-642, 2007

75. Wong SL, Shem K, Crew J: Specialized respiratory management for acute cervical spinal cord injury: a retrospective analysis. Top Spinal Cord Inj Rehabil 18:283-290, 2012

76. Yue JK, Tsolinas R, Burke JF, Deng H, Upadhyayula PS, Robinson CK, et al: Vasopressor support in managing acute spinal cord injury: a knowledge update. J Neurosurg Sci [epub ahead of print], 2017

\section{Disclosures}

Dr. Dhall has received speaking honoraria from DePuy Synthes and Globus Medical.

\section{Author Contributions}

Conception and design: Dhall, Yue, Winkler. Acquisition of data: Yue, Winkler. Analysis and interpretation of data: Yue, Winkler, Rick, Deng, Birk, Chan. Drafting the article: Dhall, Yue, Winkler, Rick, Deng, Partow, Upadhyayula, Chan. Critically revising the article: Dhall, Yue, Winkler, Rick, Deng, Birk, Chan. Reviewed submitted version of manuscript: all authors. Approved the final version of the manuscript on behalf of all authors: Dhall. Statistical analysis: Yue, Winkler. Administrative/technical/material support: Yue, Winkler. Study supervision: Dhall.

\section{Correspondence}

Sanjay S. Dhall, Department of Neurological Surgery, University of California, San Francisco, 1001 Potrero Ave., Bldg. 1, Rm. 101, San Francisco, CA 94110. email: sanjay.dhall@ucsf.edu. 